\title{
Strengthening of short circular columns using FRP materials - determining the effect of confinement
}

\author{
Vojtěch Kostiha ${ }^{1, a^{*}}$, František Girgle ${ }^{1, b}$, Anna Kučerová ${ }^{1, c}$ and Petr Štěpánek ${ }^{1, d}$ \\ ${ }^{1}$ Faculty of Civil Engineering BUT, Veveři 331/95, 60200 Brno, Czech Republic

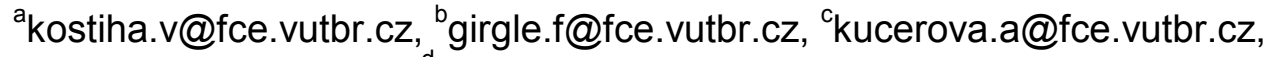 \\ dstepanek.p@fce.vutbr.cz
}

Keywords: Strengthening, reinforced concrete, FRP, fabric, confinement.

\begin{abstract}
The paper is focused on strengthening of loadbearing reinforced concrete vertical members by composite materials. These modern materials are used more and more in the last years. Usage of the FRP fabrics as confinement has several advantages, however there are some uncertainties regarding the design (eg. determining the compressive strength of confined concrete and limit strain of confined concrete). An assessment of influence of the confinement on the elements (its load bearing capacity and ductility) is necessary for design. There is a large number of analytical formulas, standardized approaches and regulations, which specify the resulting influence of the confinement. The paper draws attention to the considerable dispersion between those obtained results.

The paper presents an analysis of the influence of strengthening of reinforced concrete columns, which are confined with FRP fabric. The obtained theoretical results were compared with a real behaviour of several specimens. The short reinforced and confined concrete circular columns were used as the test specimens. The height-diameter ratio of the columns was set as $2: 1$, therefore an influence of slenderness to loadbearing capacity of the column can be neglected. Consequently, the influence of confinement can be maximized and the dispersion of results according to different methodologies can be emphasized.
\end{abstract}

\section{Introduction}

Generally, structures are exposed to a number of factors that negatively influence their reliability (material degradation due to environmental influences, changes in the load intensity, accidental actions - for example a vehicle impact, etc.) during lifetime.

In order the construction can be noted as reliable during its whole service life, it has to meet conditions defined by ULS and SLS. If any of those criteria are not fulfilled, necessary steps have to be carried out to adjust an unacceptable situation, what normally leading to maintenance or reconstruction of damaged parts of the structure.

The type of the load-bearing element (horizontal, vertical, etc.) together with type of loading (static or dynamic) significantly affects the scope and method of reconstruction (except for esthetic, time-consuming and financial criteria). The type of the proposed strengthening system is usually highly influenced by financial demands. It has to be stated, that the total costs of the reconstruction of load-bearing system includes not only the price for construction work and applied materials, but also financial losses due to delay in usage of the building. Expenses related to prospective usage of the building are one of the most neglected parameters nowadays.

The paper presents an issues of strengthening of vertical load-bearing elements - primarily columns and pillars - in detail, which are exposed to static resp. quasi-static loading. Among others possible ways of strengthening, the use of advanced composite materials for strengthening will be further discussed, especially confinement with FRP fabrics. 


\section{Use of FRP materials for strengthening}

The strengthening of vertical compressed members with composite FRP materials significantly increases the possibilities of design and offers also many advantages. Some of those advantages are for example small increase in cross-section when assuring the required load-bearing capacity, ductility and durability, increasing the rate of application and easy manipulation with light construction material and excellent resistance to the environmental impacts.

The range of currently available FRP (fibre reinforced materials) materials allows two basic ways of strengthening of columns, whose choice is determined mainly by dominant loading type [4]:

- strengthening using additional reinforcement mounted to shallow grooves parallel to the axis of the element (ie. Near Surface Mounted "NSM" reinforcement, see Fig. 1 a);

- confining by FRP fabrics/plates (see Fig. 1b) unidirectional strips, c) unidirectional or bidirectional fabric).

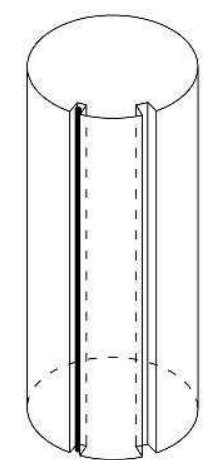

a)

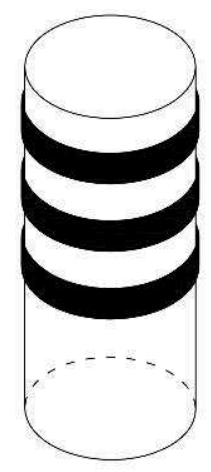

b)

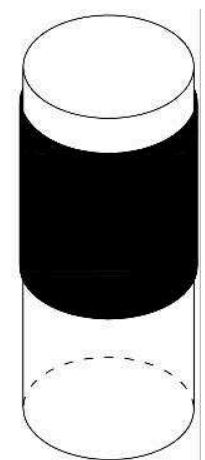

c)

Fig.1 Strengthening of RC columns using FRP materials; a) NSMR; b) horizontal strips; c) FRP jackets

Strengthening of members using NSM reinforcement brings an increase in load-bearing capacity thanks to high tensile strength of FRP materials, which is especially useful for transferring effects of the load acting on the large eccentricity [3], [4]. A necessary assumption is to ensure the sufficient bond between reinforcement and concrete.

FRP confinement induces the triaxial state of stress [1], [7], which leads to increase of the mechanical properties of the concrete as a base material. Hence, increase of load-bearing capacity and ductility of the member is achieved. Apparently, this method of strengthening is advantageous mainly for members in compression i.e. with normal force acting in the core of the section.

Based on other researches and studies (i.e. [6], [7]), it can be stated that use of FRP materials for confining is apparent in terms of efficiency. One of its main disadvantages is low fire resistance, leading to the necessity of using fireproofing layers [4]. It has to be stated, that the same disadvantage also applies to other mainly used materials like steel bandages.

The basic principles of FRP confined RC cross-section. The fundamental of strengthening technique is the inducing of the triaxial stress state. When considering the fundamental mechanical principles it is clear that axial load of the elements leads to longitudinal and also lateral deformation, which is proportional to the Poisson coefficient of the base material. In case of uniaxially loaded element, vertical cracks are gradually formed, which leads to division of the crosssection into several independent parts characterized by very high slenderness ratio and failure of the element is inevitable. The confinement delays formation and subsequent development of these cracks. Furthermore, load-bearing capacity of the column is increased as a result of lateral compression induced by restricted lateral deformations (the whole cross-section is under so-called multiaxial stress). Thanks to linear behaviour of used strengthening material, the amount of induced compression is always proportional to the strain of fabric and inversely proportional to the diameter 
of the strengthened element. It is also evident, that sufficient rigidity and strength of the confining layers are essential to maximize the effect of the confinement.

Lateral stress $\left(\sigma_{1}\right)$ for a circular cross-section can be expressed as (for derivation see eg. [6], [7]):

$$
\sigma_{1}=2 \cdot E_{\mathrm{f}} \cdot \varepsilon_{\mathrm{f}} \cdot \mathrm{t}_{\mathrm{f}} / \mathrm{D}_{\mathrm{sl}}
$$

where particular symbols denote properties of strengthening material $\left(\mathrm{E}_{\mathrm{f}}, \varepsilon_{\mathrm{f}}, \mathrm{t}_{\mathrm{f}}-\right.$ modulus of elasticity, strain and thickness of FRP fabric) resp. diameter of the strengthened RC column $\left(\mathrm{D}_{\mathrm{sl}}\right)$ (see Fig. 2).

It has to be stated, that certain amount of the lateral deformation is consumed for straightening of fibers, which is known as strengthening activation. Due to this phenomenon, interaction diagrams of confined and unconfined concrete are identical for low values of lateral strain. Hence, actual efficiency of the strengthening system is noticeable only from a certain value of the strain.

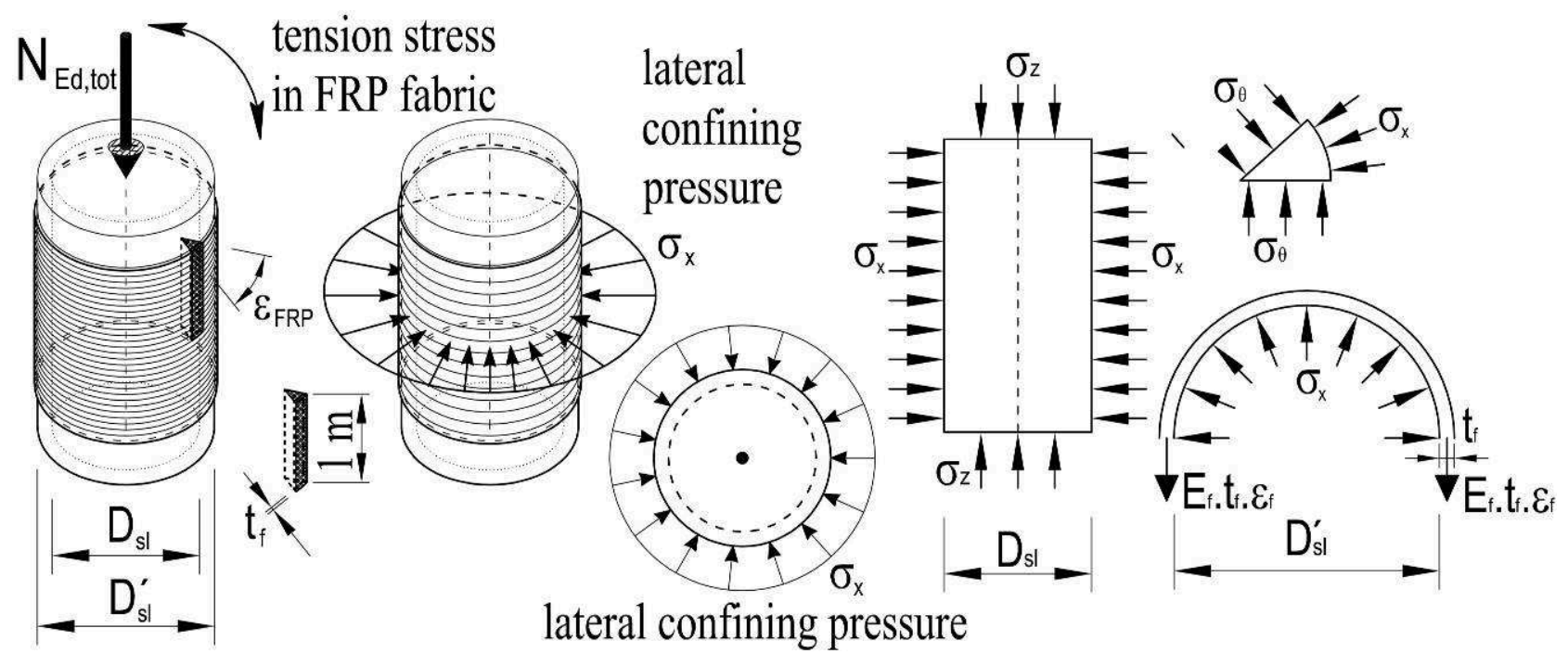

Fig. 2 Principle of strengthening by confinement - lateral stress

Factors influencing effect of confinement. As it is generally known, the resulting effect of the confinement is mainly affected by the shape and dimensions of the cross-section (effect of the confinement decreases as diameter of the cross-section increases), slenderness ratio and surface of the element. The most convenient shape of the cross-section is circular, where lateral compression is uniformly distributed along circumference of the column without causing the uneven stress concentration (see Eq. 1). For other shapes of the cross-section, lateral stress is concentrated at the corners, which results in reduction of effect of confining (see Fig. 3). It is therefore necessary to establish the efficiency of strengthening system, depending on the configuration of the crosssection. The resulting effect of confinement is further influenced by vertical arrangement of reinforcing strips of fabric (see Fig. 3), normal stiffness of reinforcing layers, orientation of fibers and also by quality of the application.

For more details about the aspects influencing resultant load-bearing capacity see for example [10]. 

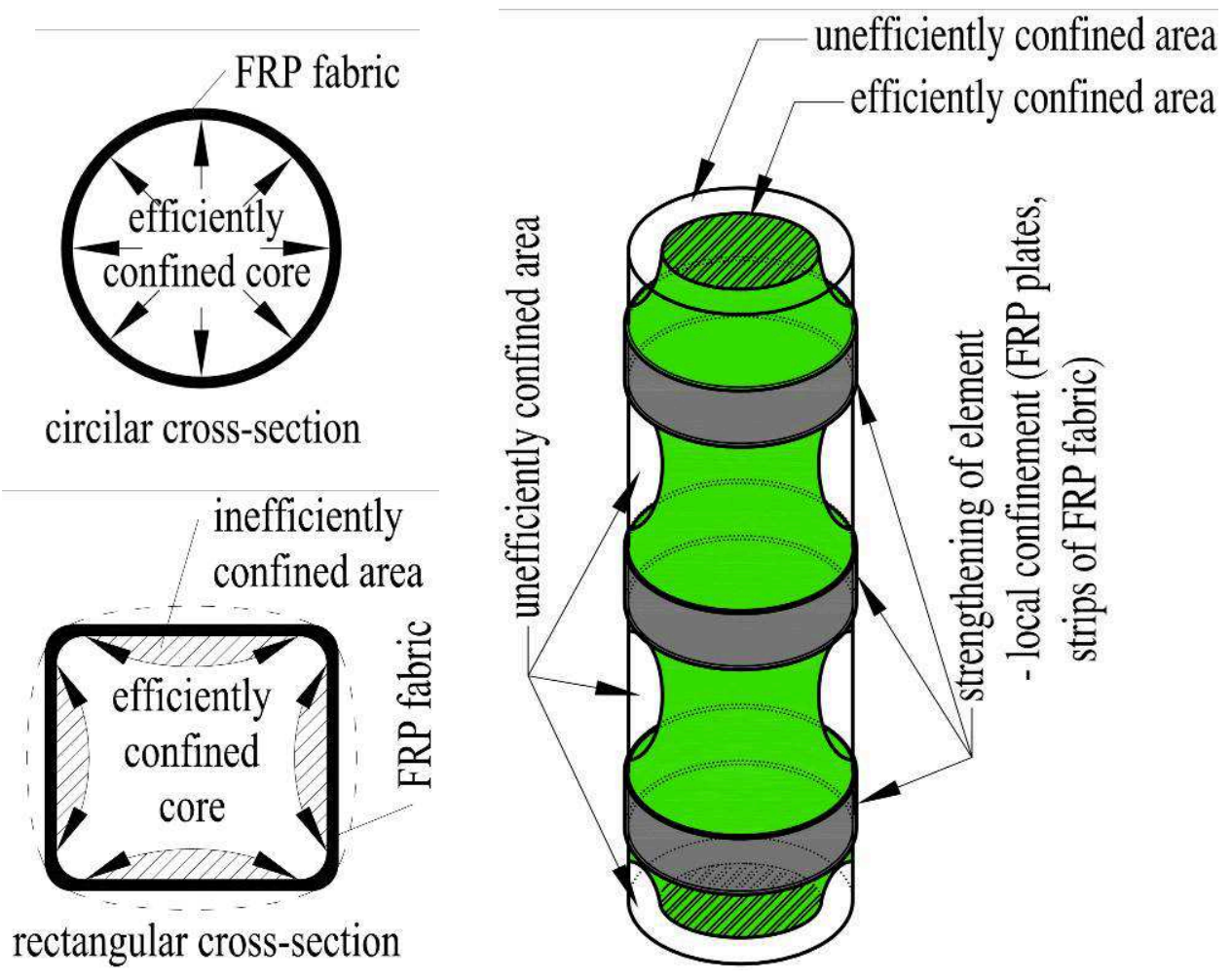

Fig. 3 Dependence of the strengthening efficiency on the cross-sectional shape of the strengthened element and strengthening system

Determination of the confinement effects. As mentioned above, elements strengthened by confinement exhibits an increase of compressive strength of confined concrete and its relative strain [1], [3], [5], [9]. Mentioned characteristics can be determined using a variety of computational models, which were derive by approximation from the conducted analytical studies and experimental work. The numerous relations were published in scientific literature, which predicted the behaviour of confined concrete, with varying degrees of accuracy. Its accuracy (and therefore usability) is primarily affected by the range of performed work and in particular by the type and configuration of specimens. According to the method of deriving, relations which were published in the scientific literature can be divided into two groups (taken from [6], [8]):

- design oriented (empirical) relations were approximated from the results of experiments so that fixed load curve obtained on its basis was as accurately as possible consistent with the results obtained from tests (accuracy of the solution depends on a number of specimens and test settings);

- analytically oriented relationships were derived from a series of analytical and numerical studies (using nonlinear analysis based on the finite element method). The correctness of the proposed relations could be verified by experiments (accuracy of the solution is determined mainly by the creation of a reliable physical model of the confined element, including the characteristics of each material and the behaviour of the entire system - e.g. the effects of the gradual activation of the fabric).

Some of the computational models are listed in Table 1, which describes historical development in analysis of behaviour of confined columns. Given relations were deliberately selected from both groups mentioned above, towards easier mutual comparison. In order to achieve completeness, computational model based on the valid normative regulation EC 1992-1-1 [1] was included. Initial relations were derived mainly for cross-sections reinforced resp. strengthened with steel reinforcement, but they are generally valid if different mechanical properties of strengthening materials are taken into account. Effectivity rate of strengthening in those relations is dependent primarily on the value of lateral strain. The similar approach is also chosen in the recently published relations, which are directly derived for the applications of composite materials (for example [6]). In 
these studies, amount of the confinement effect is also conditioned by the type of used confined material.

Table 1 Overview of the selected computational models of confined concrete

\begin{tabular}{|c|c|c|}
\hline Author & Compressive strength of confined concrete & Ultimate strain of confined concrete \\
\hline Richart 1928 & $f_{c c}^{\prime}=f_{c o}^{\prime}+4.1 \sigma_{l}$ & $\varepsilon_{c c}=\varepsilon_{c o}\left(1+20.5 \frac{\sigma_{l}}{f^{\prime}{ }_{c o}}\right)$ \\
\hline Mander 1988 & $f_{c c}^{\prime}=f_{c o}^{\prime}\left[2.254 \sqrt{1+\frac{7.94 \sigma_{l}}{f_{c o}^{\prime}}}-2 \frac{\sigma_{l}}{f_{c o}^{\prime}}-1.254\right]$ & $\varepsilon_{c c}=\varepsilon_{c o}\left[1+5\left(\frac{f^{\prime}{ }_{c c}}{f_{c o}^{\prime}}-1\right)\right]$ \\
\hline Eurocode EC 1992-1 & $\begin{array}{c}f_{c k, c}=f_{c k}\left(1.0+5.0 \frac{\sigma_{l}}{f_{c k}}\right) \text { for } \sigma_{l}<0.05 f_{c k} \\
f_{c k, c}=f_{c k}\left(1.125+2.5 \frac{\sigma_{l}}{f_{c k}}\right) \text { for } \sigma_{l}>0.05 f_{c k}\end{array}$ & $\begin{aligned} \varepsilon_{c 2, c} & =\varepsilon_{c 2}\left(\frac{f_{c k, c}}{f_{c k}}\right)^{2} \\
\varepsilon_{c u 2, c} & =\varepsilon_{c u 2}+0.2 \frac{\sigma_{l}}{f_{c k}}\end{aligned}$ \\
\hline $\begin{array}{c}\text { Cusson \& Paultre } \\
1995\end{array}$ & $f_{c c}^{\prime}=f_{c o}^{\prime}\left[1+2.1\left(\frac{\sigma_{l}}{f_{c o}^{\prime}}\right)^{0.70}\right]$ & $\varepsilon_{c c}=\varepsilon_{c o}+0.21\left(\frac{\sigma_{l}}{f_{c o}^{\prime}}\right)^{1.70}$ \\
\hline Kono 1998 & $f_{c c}^{\prime}=f_{c o}^{\prime}\left(1+0.0572 \sigma_{l}\right)$ & $\varepsilon_{c c}=\varepsilon_{c o}+0.28 \varepsilon_{c o} \sigma_{l}$ \\
\hline Lam \& Teng 2002 & $f_{c c}^{\prime}=f_{c o}^{\prime}+2.0 \sigma_{l}$ & $\begin{array}{l}\varepsilon_{c c}=\varepsilon_{c o}\left[2+k_{2}\left(\frac{\sigma_{l}}{f^{\prime} c o}\right)\right] \\
\text { where } k_{2}=15 \text { for CFRP }\end{array}$ \\
\hline Lam \& Teng 2003 & $f_{c c}^{\prime}=f_{c o}^{\prime}+3.3 \sigma_{l}$ & $\begin{array}{c}\varepsilon_{c c}=\varepsilon_{c o}\left[2+k_{2}\left(\frac{\sigma_{l}}{f^{\prime}{ }_{c o}}\right)\left(\frac{\varepsilon_{f r p}}{\varepsilon_{c o}}\right)^{0.45}\right] \\
\text { where } k_{2}=5.53 \text { for CFRP }\end{array}$ \\
\hline Bisby 2005 & $\begin{array}{c}f_{c c}^{\prime}=f_{c o}\left(1.0+2.425 \frac{\sigma_{l}}{f^{\prime} c o}\right) \\
{f^{\prime}{ }_{c c}}^{\prime}=f_{c o}^{\prime}\left[1+2.217\left(\frac{\sigma_{l}}{f_{c o}^{\prime}}\right)^{0.911}\right] \\
f_{c c}^{\prime}=f_{c o}^{\prime}\left[1+3.587\left(\sigma_{l}\right)^{0.84}\right]\end{array}$ & $\begin{array}{l}\varepsilon_{c c}=\varepsilon_{c o}+k_{2}\left(\frac{\sigma_{l}}{f^{\prime} c o}\right) \\
\text { CFRP: } k_{2}=0.0240 \\
\text { AFRP: } k_{2}=0.0536 \\
\text { GFRP: } k_{2}=0.0137\end{array}$ \\
\hline Youssef 2007 & $f_{c c}^{\prime}=f_{c o}^{\prime}\left[1+2.25\left(\frac{\sigma_{l}}{f_{c o}^{\prime}}\right)^{1.25}\right]$ & $\varepsilon_{c c}=0.003368+0.259\left(\frac{\sigma_{l}}{f_{c o}^{\prime}}\right) \sqrt{\frac{f_{f}}{E_{f}}}$ \\
\hline ACI 440.2R-08;-09 & $\begin{array}{c}f_{c c}^{\prime}=f_{c o}^{\prime}+3.3 \psi_{f} \sigma_{l} \\
; \psi_{f}=0.95\end{array}$ & $\begin{array}{c}\varepsilon_{c c}=\varepsilon_{c o}\left[1.5+12\left(\frac{\sigma_{l}}{f^{\prime}}\right)\left(\frac{\varepsilon_{F o, w}}{\varepsilon_{c o}}\right)^{0.45}\right] \\
\varepsilon_{c u 2, c}=\varepsilon_{c u 2}+0.2 \frac{\sigma_{l}}{f_{c k}}\end{array}$ \\
\hline Yu \& Teng 2011 & $f_{c c}^{\prime}=f_{c o}^{\prime}+3.5 E_{l}\left(1+6.5 \frac{f_{c o}^{\prime}}{E_{l}}\right) \varepsilon_{h, r u p}$ & $c c=0.0033+0.6\left(\frac{E_{l}}{f_{c o}^{\prime}}\right)^{0.8}\left(\varepsilon_{h, \text { rup }}\right)^{1.45}$ \\
\hline
\end{tabular}

Symbols used in Table 1:

$\mathrm{f}_{\mathrm{ck}, \mathrm{c}}, \mathrm{f}_{\mathrm{ck}} \quad$ - characteristic cylinder compressive strength of confined resp. unconfined concrete (according to ČSN EN 1992-1-1 [1]);

$\mathrm{f}^{\prime}{ }_{\mathrm{cc}}, \mathrm{f}^{\prime}{ }_{\text {co }}$ - specific cylinder compressive strength of confined resp. unconfined concrete (according to other regulations);

$\varepsilon_{\mathrm{cu} 2, \mathrm{c}}, \varepsilon_{\mathrm{c} 2, \mathrm{c}}-$ ultimate compressive strain in the concrete corresponding to $\mathrm{f}_{\mathrm{ck}, \mathrm{c}}$, resp. $\mathrm{f}_{\mathrm{ck}}$;

$\varepsilon_{\mathrm{cc}}, \varepsilon_{\mathrm{co}} \quad$ - compressive strain in the concrete corresponding to $\mathrm{f}_{\mathrm{cc}}^{\prime}$, resp. $\mathrm{f}_{\mathrm{co}}^{\prime}$;

$\sigma_{1} \quad-$ effective lateral compression stress due to confinement. 


\section{Model example - comparison of computational relationships}

In order to compare values obtained from aforementioned relationship with values determined experimentally simple model case of vertically compressed member was considered. Reinforced concrete element of circular cross-section with a diameter of $200 \mathrm{~mm}$ and a height of $400 \mathrm{~mm}$ was taken into account. The dimensions of the element were deliberately chosen to eliminate the influence of slenderness and to maximize the developed differences in the obtained values. The test specimens (cube, beams), which were made simultaneously with samples of short columns, the mean compressive strength was determined $\mathrm{f}_{\mathrm{cm}}=33.62 \mathrm{MPa}$ in accordance with the procedure described in literature [2], [12]. Measured concrete strength was subsequently used for calculation. The specimens of tested elements (short column) was reinforced by the longitudinal bars with a diameter of $8 \mathrm{~mm}$ and by the transverse reinforcement with diameter of $6 \mathrm{~mm}$ in spiral form (steel class $\mathrm{B} 500, \mathrm{f}_{\mathrm{ym}}=574.06 \mathrm{MPa}, \mathrm{E}_{\mathrm{sm}}=199.07 \mathrm{GPa}$ - these values were specified by tests; see Fig. 4). The confinement is considered in one layer over the entire area of the element by unidirectional carbon fiber wrap SikaWrap $600 \mathrm{C} / 120$ [11]. The properties of laminate layers have been determined experimentally, wherein the thickness $\mathrm{t}_{\mathrm{f}}=1.24 \mathrm{~mm}$, the modulus of elasticity $\mathrm{E}_{\mathrm{f}}=86.42$ $\mathrm{GPa}$, the limit tensile strength $\mathrm{f}_{\mathrm{f}}=702.289 \mathrm{MPa}$ and the ultimate strain $\varepsilon_{\mathrm{f}}=0.813 \%$. Compared to the values given by manufacturer (thickness of laminated layer of $1,3 \mathrm{~mm}$, the limit tensile strength of approximately $580 \mathrm{MPa}$, modulus of elasticity of $50 \mathrm{GPa}$ and ultimate strain of $0.60 \%$ - taken from the manufacturer Sika, Ltd.), there was an increase in the parameters of the laminate.

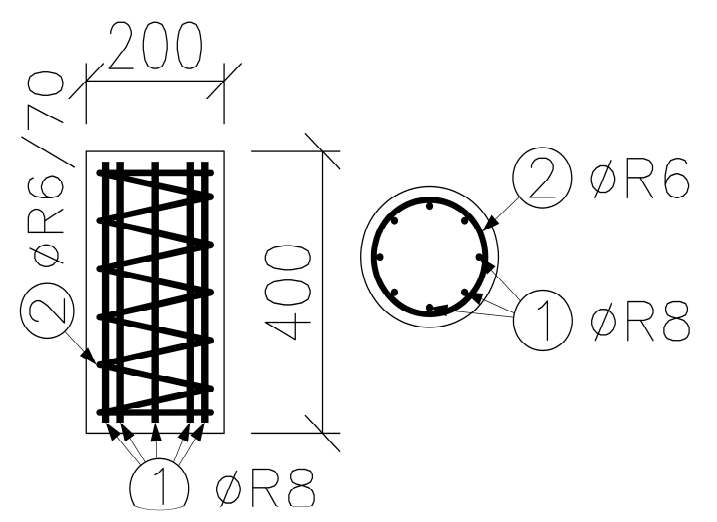

Fig. 4 Geometry and reinforcement of test specimen

The resulting values determined on the basis of the relationships shown in Table 1 are presented in Table 2. Several simplifying assumptions were accepted in the model to maximize the differences of individual approaches: zero initial load acting on the strengthened element before applying the fabric (ie. full utilization of deformability of the element until its failure without the initial restrictions) and neglecting the gradual activation of fabric (part of strain of the reinforced element is consumed on straightening of fiber in fabric).

Table 2 Overview of the results from selected computational models of confined concrete

\begin{tabular}{|c|c|c|c|c|c|}
\hline Design approaches & $\mathbf{f}_{\mathrm{cc}}$ & $\overline{\varepsilon_{\text {cu.c. }}}$ & Design approaches & $\mathbf{f}_{\mathrm{cc}}$ & $\varepsilon_{\mathrm{culc}}$ \\
\hline Richart (1928) & 69,32 & $\mathbf{0 , 0 2 2 1}$ & Lam \& Teng (2003) & 62,36 & $\mathbf{0 , 0 1 3 4}$ \\
\hline Mander (1988) & 72,91 & 0,0137 & \multirow{3}{*}{$\begin{aligned} \text { Bisby (2005) } & \text {-for CFRP } \\
& - \text { for GFRP } \\
& - \text { for AFRP }\end{aligned}$} & 54,74 & $\mathbf{0 , 0 0 9 7}$ \\
\hline ЕС 1992-1-1 & $\mathbf{5 9 , 5 9}$ & 0,0327 & & 55,39 & 0,0070 \\
\hline Cusson \& Paultre (1995) & 61,05 & 0,0246 & & 72,39 & $\mathbf{0}, \mathbf{0 1 7 4}$ \\
\hline Kono (1998) & $\mathbf{5 0 , 3 7}$ & $\mathbf{0 , 0 1 2 0}$ & Youssef (2007) & 47,60 & $\mathbf{0 , 0 0 9 4}$ \\
\hline Lam \& Teng (2002) & 51,04 & 0,0206 & $A C I 440.2 R(2008)$ & 62,36 & 0,0125 \\
\hline & & & Yu \& Teng (2011) & 57,88 & 0,0122 \\
\hline
\end{tabular}


The dispersion of mean value of compressive strength of confined concrete $\left(f_{c c}\right)$ is in the range from 47.60 MPa to $72.91 \mathrm{MPa}$, based on the above simplifying assumptions, which represents an increase of strength in the range of $41.58 \%-116.87 \%$ in comparison with the referential (unconfined) element. As highlighted in Table 2, the difference between the highest and the lowest values of compressive strength of confined concrete is very significant.

Interaction diagrams (ID) of the above described element of short columns were completed on the basis of relation from Table 1 and they are presented in Fig. 8. When calculating the points of ID the limit strain of confined concrete $\left(\varepsilon_{\mathrm{cc}}\right)$ should be also taken into account. The value of ultimate strain suffers from significant dispersion as well as compressive strength (see Table 2) and becomes one of the reasons which causes an increase in differences between introduced relationships. Resistance of cross-section determined according to [1] lies approximately in the middle of the resultant dispersion of values.

The value of ultimate strain $\varepsilon_{\mathrm{cc}}$ determined according to [1] (see Table 2) is considerably overestimated in comparison with other values, which is probably due to the derivation of relationship for the confinement of the column with steel reinforcement or jackets. This assumption is reflected in the stress-strain diagram of confined concrete according to [1], when after reaching the ultimate strain plasticization of the element occurs (typical for steel reinforcement). For FRP materials with linear stress-strain diagram until failure, it is necessary to modify the diagram of confined concrete and restrict the value of ultimate strain.

Figure 5 shows a comparison of the parabolic-rectangular stress-strain diagram of unconfined and confined concrete determined according to [1], which was considered in the calculation of the interaction diagram (see Fig. 8, curve labeled EC2). For comparison the stress-strain diagram of confined concrete according to Lam \& Teng (2003) [6] is also illustrated, since it is quite used design procedure of strengthening by FRP materials. From two mentioned design diagrams the increase in strength of confined concrete is evident as well as apparent increase in its ductility. The stress-strain diagram of confined concrete according to EC2 was limited by strain $\varepsilon \mathrm{cc} 2$ (denoted according to [1]) for the above reasons. The ultimate strength of strengthening material is achieved right at mentioned strain.

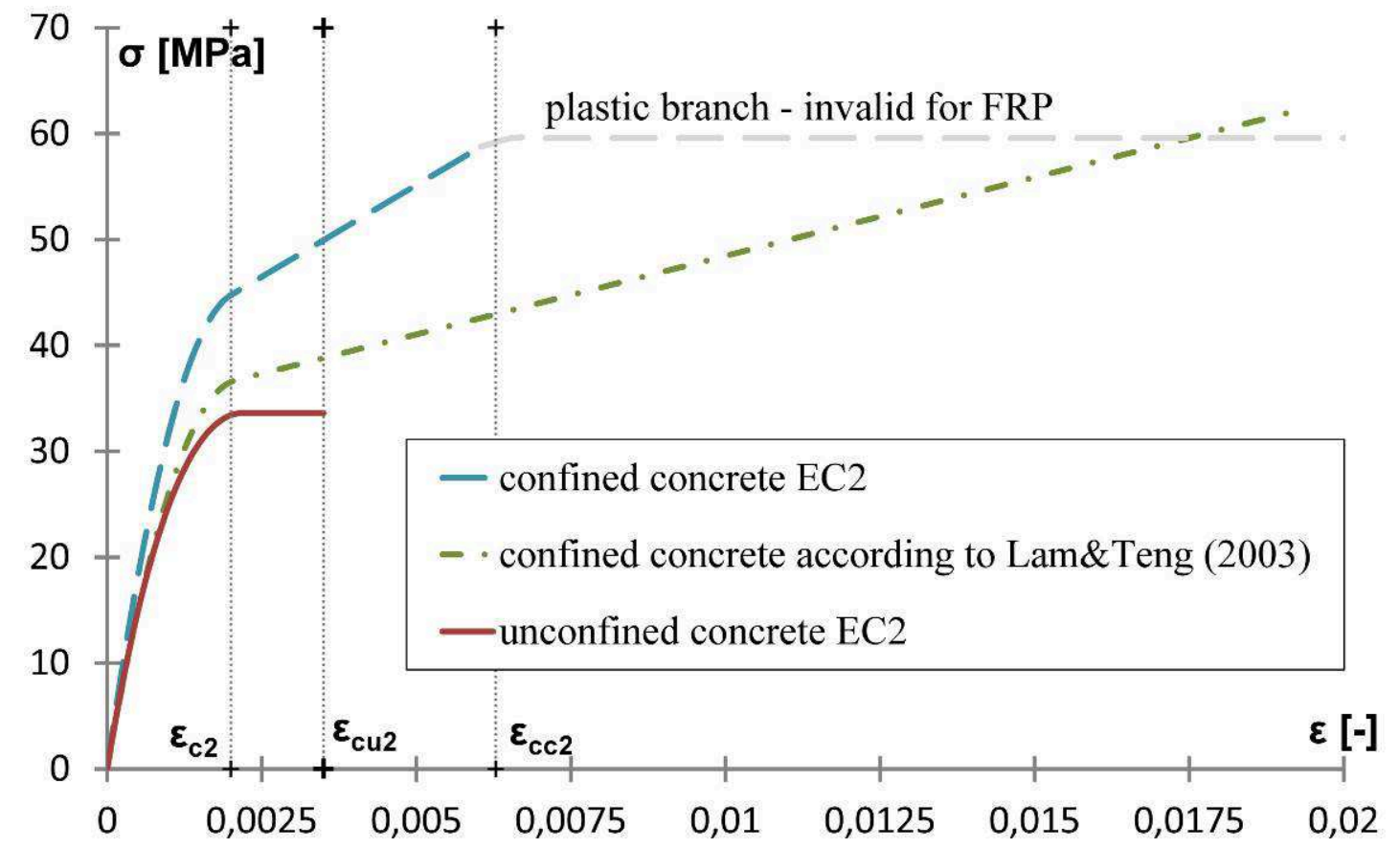

Fig. 5 The working diagram of unconfined/confined concrete

From the above results of model studies it is evident that the choice of the applied approach (and the related stress-strain diagram of confined concrete) significantly influences the obtained results, which should be taken into account when designing this type of strengthening. The resulting difference of obtained values is in the order of tens of percent. 


\section{The experimental verification of the theoretical assumptions}

Above mentioned results were compared with experimentally obtained values. Test series included 4 pieces of test samples, three of which were strengthened as described above. Applications of FRP fabrics required surface treatment of concrete specimens by sandblasting which ensures sufficient bond between the concrete and the bonded layer of fabric. The fourth specimen was considered as the referential, and therefore it was not confined. Together with the test specimens, concrete beams and cubes were manufactured in order to determine required properties of concrete - concrete compressive strength and modulus of elasticity.

During the load test the individual elements were continuously loaded by compressive force until to its failure at a test facility - only the axial compression force on the element was applied, without any effects of bending. This allowed to directly compare the results of real behaviour with obtained theoretical calculation. This theoretical case of loading (corresponds to the point " 0 " in ID) is justified for the test specimen (short column), since the influence of eccentricities can be neglected.

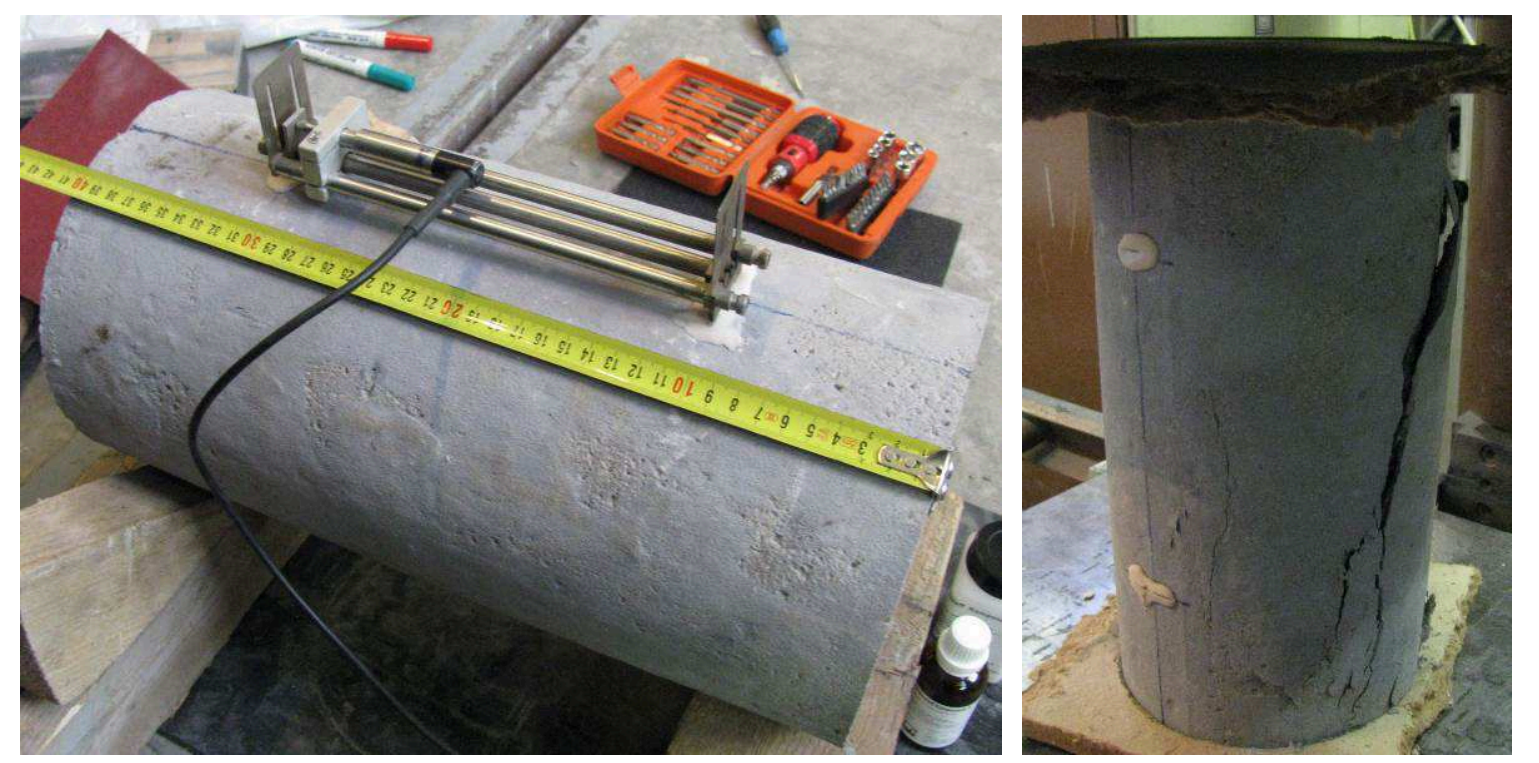

a) preparation of referential specimen

b) failure mode of referential specimen

Fig. 6 The loading test of the referential specimen

During the test values of force and corresponding deformation were continuously measured. These deformations were measured by displacement transducers on two opposite sides of the specimen (see Fig. 6). Furthermore strain gauges were installed on the fabric perpendicular to the axis of the specimen, allowing the analysis of behaviour of FRP fabric during the testing and mainly they allow to determine lateral strain important for activation of confinement. Test configuration and failure mode of specimen are shown on Fig. 7.

It can be said, that chosen method of strengthening is accurate, based on the results presented in Fig. 8, resp. Fig. 9. There is a noticeable difference in the behaviour of unstrengthened (referential) and strengthened (confined) specimen, that confirms the assumption presented in the literature. Expected failure can be observed on all specimens. Due to the confinement ultimate resistance was increased of $103 \%$, i.e. in this case from $1258 \mathrm{kN}$ (measured on the referential specimen) to 2556 $\mathrm{kN}$ (strengthened specimen). The ultimate resistance without the effect of confining by transversal reinforcement was increased of $56.3 \%$ (from $36.525 \mathrm{MPa}$ to $57.091 \mathrm{MPa}$ ). 


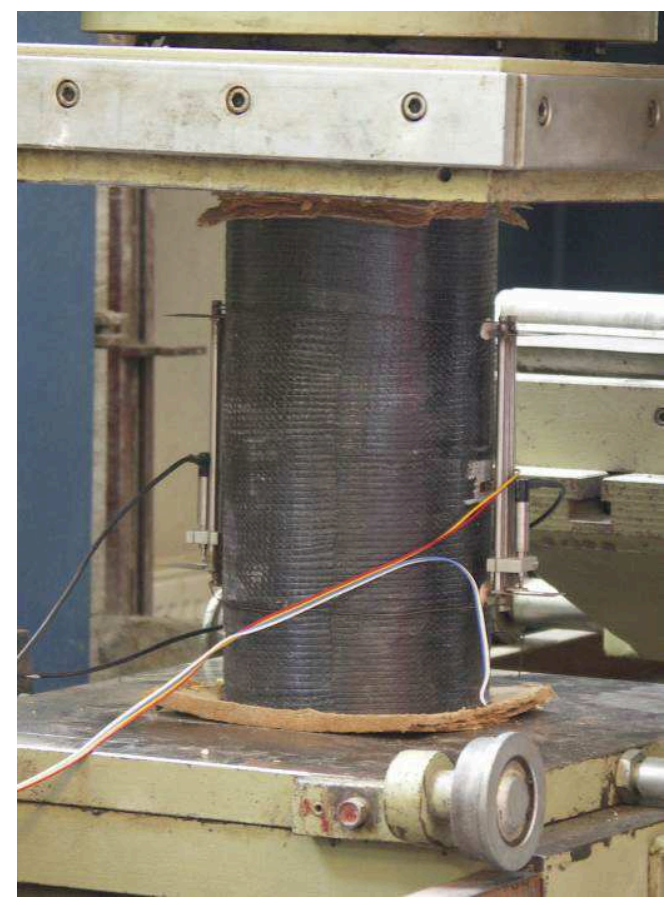

a) loading of confined specimen

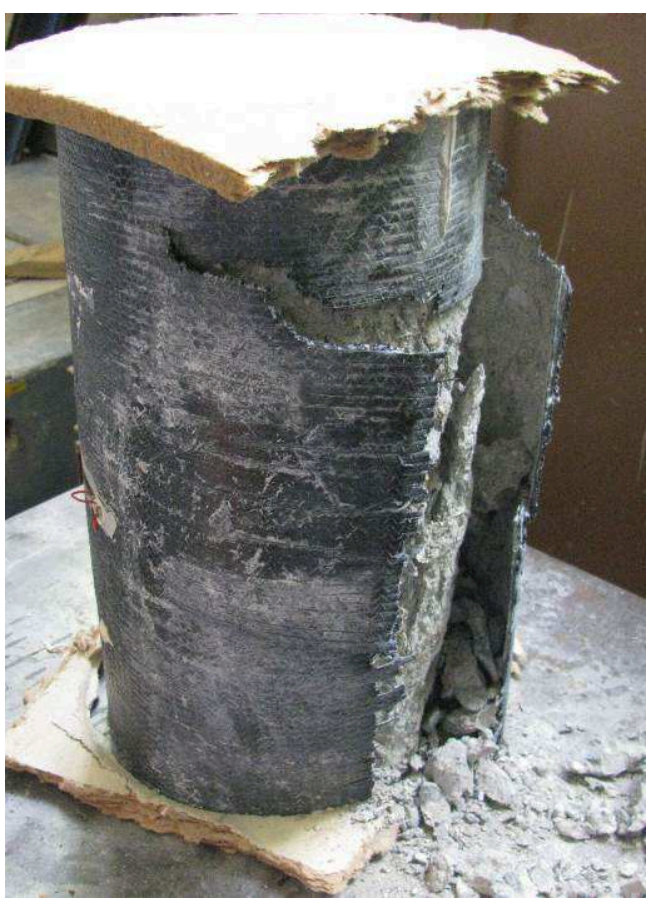

b) failure mode of confined specimen

Fig. 7 The loading test of confined specimen

Increase in ductility is also confirmed, since the ultimate strain for confined specimen was larger twice (2.25\% for unconfined resp. 4.82\%o for confined specimen, see Fig. 9). Nevertheless, the measured values of strain of confined specimen did not reach the expected values, predicted by relations. Failure of test specimens was reached for lower values of lateral strain when compared the theoretical predictions (see Fig. 9 and Table 2).

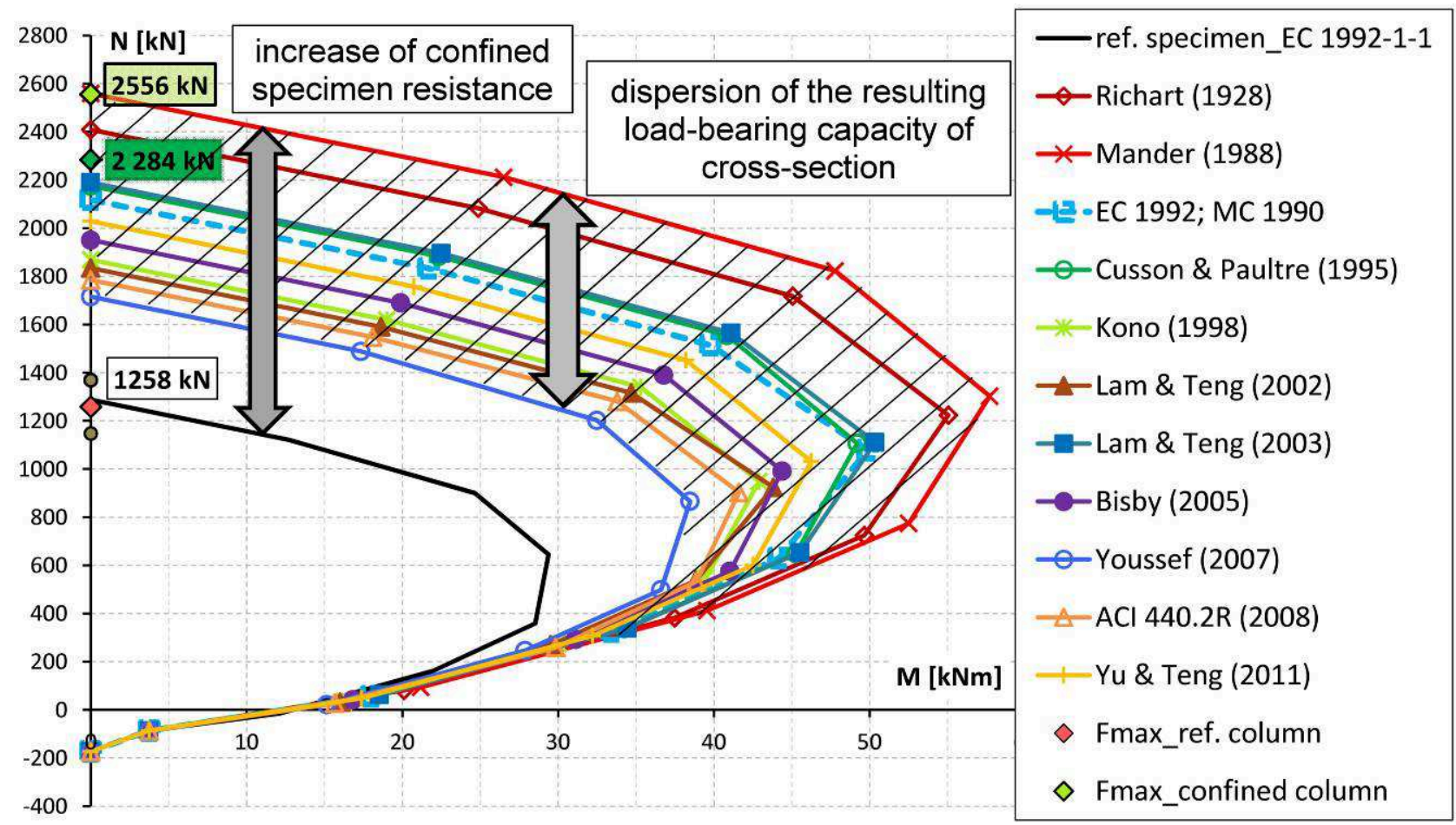

Fig. 8 Dispersion of unconfined/confined tests specimens

Actual values of ultimate lateral strain of FRP fabrics were also determined based on maximal values reached before failure of the fabric. According to the manufacturer, limit values of lateral 
strain is $6 \%$, which represents the design value and therefore should be conservative in terms of design. Experimentally obtained values of lateral strain were in range from $4.40 \%$ to $5.23 \%$ (mean values was $4.79 \%$ ), which is significantly lower than the value specified by manufacturer. This difference could be caused by inaccuracy which arisen during application of laminate layer or it could be caused by improper fabric-adhesive ratio, which is hard to achieve in practice. When considering the results which were obtained, further experiments have to be planned to gain more precise information about behaviour of confined columns with FRP fabric.

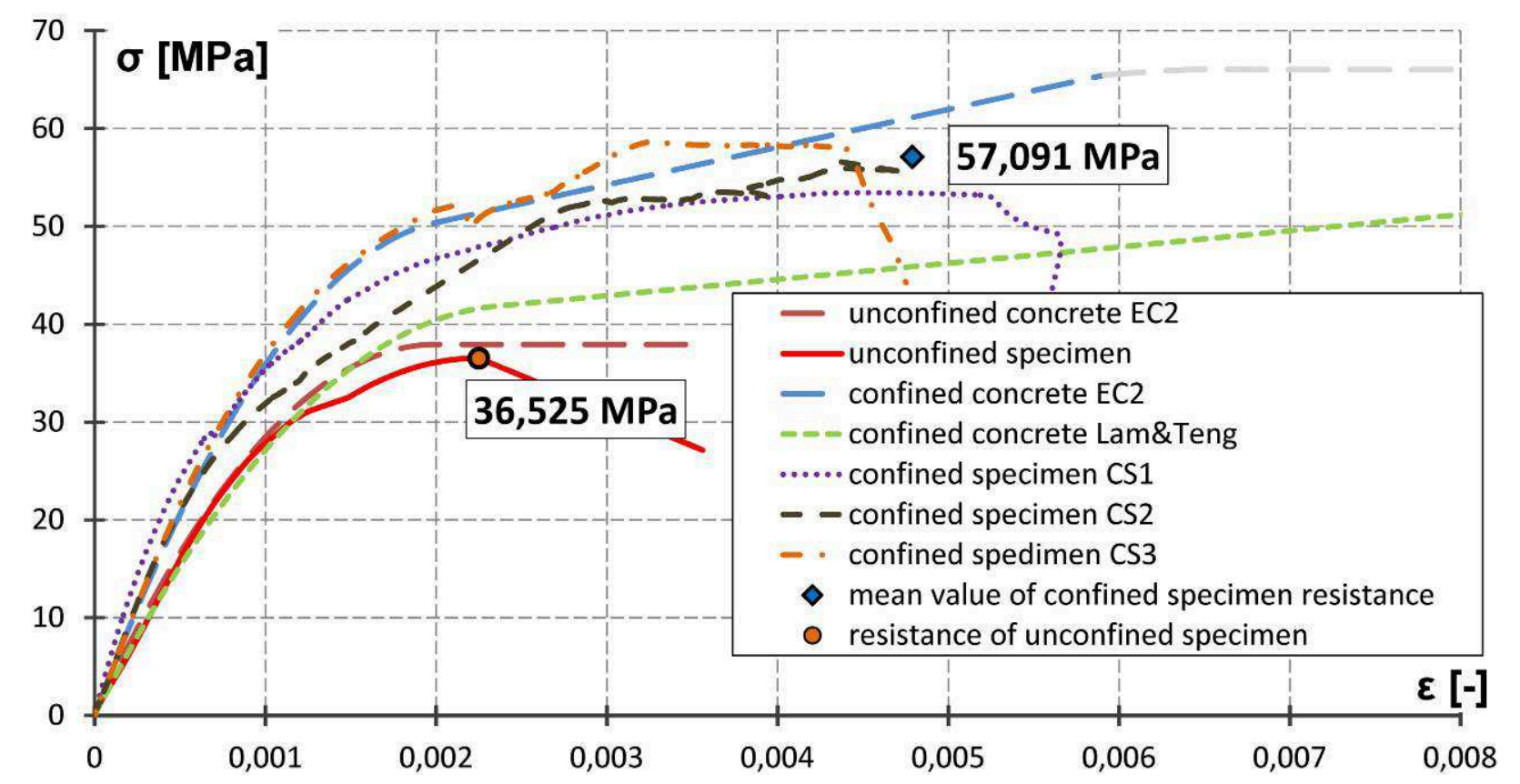

Fig. 9 The working diagram of the unconfined/confined test specimens (without the effect of confining by transversal reinforcement)

\section{Evaluation of the effect of column diameter and number of fabric layers}

Further experiments carried out at Faculty of Civil Engineering VUT are pointed to verifying the basic factors influencing the effects of strengthening by confinement i.e. effects of column diameter (size effect) and effects of strengthening type (number of fabrics).

Experimental specimens were made from plain concrete (excluding the impact of reinforcement on the load-bearing capacity) with circular cross-section and height-diameter ratio 2:1. The group of columns with diameter of $100 \mathrm{~mm}$ was labeled as $\mathrm{K}$ and second group with diameter of $185 \mathrm{~mm}$ was labeled as T. Mean value of concrete compressive strength was $\mathrm{f}_{\mathrm{cm}}=36.39 \mathrm{MPa}$. The columns were loaded by axial compression to maximize the effect of confinement. Specimens were loaded in "soft mode" (force increment) until failure. Effects of number of fabric layers can be observed, since specimens were confined by both, one and three layers of fabric (specimens $1 \mathrm{~K}$ resp. $1 \mathrm{~T}$ and $3 \mathrm{~K}$ resp. 3T).

Experimental results confirmed the assumptions that diameter of column and number of layers affected efficiency of confinement, what is evident from the ratio of the confined and unconfined column strength $\mathrm{f}_{\mathrm{cc}} / \mathrm{f}_{\mathrm{c} 0}$ (see Table 3 ). When the diameter of column was increased of $85 \%$ the ratio of strength $\mathrm{f}_{\mathrm{cc}} / \mathrm{f}_{\mathrm{c} 0}$ of the confined and unconfined column decreased from 2.57 to 1.9 in case of specimens $1 \mathrm{~K}$ and $1 \mathrm{~T}$, resp. from 4.12 to 3.23 for specimens $3 \mathrm{~K}$ and $3 \mathrm{~T}$. Similar trend could be observed when regarding the number of fabric layers applied. 
Table 3 Results of resistance of short column from plain concrete

\begin{tabular}{|c|c|c|c|c|c|c|c|}
\hline specimen & $\begin{array}{l}F_{\max } \\
{[\mathrm{kN}]}\end{array}$ & $\begin{array}{c}\sigma_{\max } \\
{[\mathrm{MPa}]}\end{array}$ & $\begin{array}{c}\mathbf{f}_{\mathrm{cc}} / \mathbf{f}_{\mathrm{c} 0} \\
{[-]} \\
\end{array}$ & specimen & $\begin{array}{l}F_{\max } \\
{[\mathrm{kN}]}\end{array}$ & $\begin{array}{c}\sigma_{\max } \\
{[\mathrm{MPa}]}\end{array}$ & $\begin{array}{c}\mathbf{f}_{\mathbf{c c}} / \mathbf{f}_{\mathbf{c} 0} \\
{[-]}\end{array}$ \\
\hline REF.K & 285,77 & 36,39 & - & REF.T & 1001,54 & 35,32 & - \\
\hline $1 K .1$ & 733,19 & 93,35 & 2,57 & $1 T .1$ & 1772,97 & 65,96 & 1,87 \\
\hline $1 K .2$ & 742,58 & 94,55 & 2,60 & $1 T .2$ & 1731,87 & 64,43 & 1,82 \\
\hline $1 K .3$ & 800,49 & 101,92 & 2,80 & $1 T .3$ & 1902,20 & 70,77 & 2,0 \\
\hline $1 K .4$ & 662,69 & 84,38 & 2,32 & & & & \\
\hline $3 K .1$ & 1030,22 & 131,17 & 3,61 & $3 T .1$ & 3076,48 & 108,51 & 3,07 \\
\hline $3 K .2$ & 1123,63 & 143,06 & 3,93 & $3 T .2$ & 3163,08 & 117,67 & 3,33 \\
\hline $3 K .3$ & 1373,41 & 174,87 & 4,81 & $3 T .3$ & 3113,41 & 115,83 & 3,28 \\
\hline
\end{tabular}

Used symbols: $\quad \mathrm{F}_{\max }-$ maximal force at failure of specimen

$\sigma_{\max }-$ maximal compressive strength

\section{Conclusion}

Strengthening of the column by confinement with FRP fabrics leads to development of triaxial stress state in compressed confined element, similar to the application of lateral reinforcement (stirrups, circular spirals). Furthermore it leads to increase of concrete compressive strength and its ultimate deformation capacity - element exhibits more ductile behaviour and better resists the impacts of accidental loads. Paper emphasizes the fact, that there is a considerable discrepancy when key characteristics are determined. Therefore, it can be quite difficult for designers to choose the appropriate relationship, which could optimally describe the behavior of strengthened element and assess the load bearing capacity with sufficient rate of reliability.

The aim of this study is to determine some practical recommendations which, based on a work performed and in a full accordance with valid normative regulations and standards, will facilitate the safe design and allow the expansion of this progressive and promising way of strengthening of vertical elements in compression. The newly discovered facts from ongoing research will be presented to public in the future papers.

\section{Acknowledgement}

The presented results were obtained with the financial support of the Technology Agency of the Czech Republic project TA04010881 "Determination of the long term reliability of composite reinforcement due to the increasing of their utility properties", the project No. LO1408 "AdMaS UP - Advanced Materials, Structures and Technologies", supported by Ministry of Education, Youth and Sports under the „National Sustainability Programme I" and Brno University of Technology internal grant agency project FAST-S-15-2899 "The use of advanced FRP mate rials in durable structures".

\section{References}

[1] ČSN EN 1992-1-1 (73 1201) Navrhování betonových konstrukcí. Č́st 1-1: Obecná pravidla a pravidla pro pozemní stavby, 2006

[2] ČSN EN 206-1 (73 2403): Beton - Č́st 1: Specifikace, vlastnosti, výroba a shoda, 2001

[3] ACI 440.2R-02: Guide for the Design and Construction of Externally Bonded FRP Systems for Strengthening Concrete Structures, ACI Committee 440, 2002, ISBN 0-87031-088-7 
[4] Bulletin 14: Externally bonded FRP reinforcement for RC structures, technical report prepared by a working party of Task Group 9.3, FRP (Fibre Reinforced Polymer) reinforcement for concrete structures. 1st pub. Lausanne: International Federation for Structural Concrete, 2001, 139 s. Bulletin Féderation internationale du béton (fib). ISBN 2-88394-054-1

[5] CEB-FIP Model Code 1990, 1. Vydání, London: Comite Euro International du Beton, 1998, 186 s. ISBN 0727716964

[6] Ozbakkaloglu T., Jian C. Lim, Vincent T.: FRP-confined concrete in circular sections: Review and assessment of stress-strain models, Engineering Structures, Volume 49, April 2013, pages 1068-1088

[7] Hernández H., Jara J. M., Jara M.: Revision of constitutive models for repairing bridge columns with fiber polymers, International Journal of Engineering, Science and Technology, Volume 3, No 4 2011

[8] Mander J. B., Priestley M. J. N., Park R.: Theoretical Stress-Strain Model for Confined Concrete, Journal of Structural Engineering, Volume 114, Issue 8, September 1988, pages 18041826

[9] Campione G., Miraglia N.: Strength and strain capacities of concrete compression members reinforced with FRP, Cement and Concrete Composites, Volume 25, Issue 1, January 2003, pages $31-41$

[10]Bilčík J., Gajdošová K.: Zásady zosilňovania betónových konštrukcií lepenou CFRP výstužou, Beton TKS, 3/2014, 68 - 72, 2014, ISSN 12133116

[11]Uhlíková jednosměrná tkanina SikaWrap 600 C/120, výrobce: Sika CZ, s.r.o. Dostupné z:http://cze.sika.com/cs/produkty_a_reseni/dokumentace/PDS/PDS_G_Sika_Wrap.html

[12]ČSN EN 12390-3 (73 1302) Zkoušení ztvrdlého betonu - Část 3: Pevnost v tlaku zkušebních těles, 2002 